\title{
LA PRESA DE LA GARGANTA DEL CIERVO, S. XII (SEGURA DE LA SIERRA, JAÉN, ESPAÑA): APORTACIONES A LA INGENIERÍA HIDRÁULICA ANDALUSÍ
} THE DAM IN GARGANTA DEL CIERVO, 12TH CENTURY (SEGURA DE LA SIERRA, JAÉN, ESPAÑA):
CONTRIBUTIONS TO ANDALUSIAN HYDRAULIC ENGINEERING

VICENTE SALVATIERRA CUENCA

Universidad de Jaén

FRANCISCO GÓMEZ CABEZAS

\section{Resumen}

En este texto analizamos una notable presa islámica localizada en la Sierra de Segura, fechada en el siglo XII. Su envergadura, $11 \mathrm{~m}$ de altura y $9 \mathrm{~m}$ de grosor, su situación en una zona sustancialmente llana, su técnica de fabricación, el pantano que generaba, etc. la convierten en principio en un elemento muy atípico dentro de la arquitectura de regadío andalusí. Además de realizar su descripción, nos proponemos discutir hasta qué punto la finalidad de esta estructura era realmente diferente a lo que se hacía en la época, y si supone por tanto un cambio tecnológico y social. O si su configuración escondía otros objetivos.

Palabras clave. Regadío andalusí, presa de derivación, tecnología, siglo XII.

\begin{abstract}
In this text we analyze a remarkable Islamic dam located in Sierra de Segura, dated from the 12th century. The size of the dam, $11 \mathrm{~m}$ high and $9 \mathrm{~m}$ thick, its location in a mostly flat area, the technique used to build it, the reservoir that it created, etc. makes dams a very singular element among the irrigation architecture in Al-Andalus. In addition to describing the dam, we also intend to discuss to which point the purpose of this structure was truly different from what was usually done at that time, and, therefore, if it means both a technological and social change, or if its configuration hid other objectives.
\end{abstract}

Key words. Andalusí irrigation, dam, technology, $12^{\text {th }}$ Century.

Para citar este artículo / To cite this article: Salvatierra Cuenca, V. y Gómez Cabezas, F. (2016). La presa de la garganta del ciervo, s. XII (Segura de la Sierra, Jaén, España): aportaciones a la ingeniería hidráulica andalusí. Lucentum, $X X X V$, 307-322. doi: 10.14198/LVCENTVM2016.35.16

Para enlazar con este artículo / To link to this article: http://dx.doi.org/10.14198/LVCENTVM2016.35.16 


\title{
LA PRESA DE LA GARGANTA DEL CIERVO, S. XII (SEGURA DE LA SIERRA, JAÉN, ESPAÑA): APORTACIONES A LA INGENIERÍA HIDRÁULICA ANDALUSÍ
}

\author{
THE DAM IN GARGANTA DEL CIERVO, 12TH CENTURY (SEGURA DE LA SIERRA, JAÉN, ESPAÑA): \\ CONTRIBUTIONS TO ANDALUSIAN HYDRAULIC ENGINEERING
}

\author{
VICENTE SALVATIERRA CUENCA \\ Universidad de Jaén
}

FRANCISCO GÓMEZ CABEZAS

\section{INTRODUCCIÓN}

Desde finales de los años 70 del siglo XX se han realizado numerosos estudios arqueológicos sobre el regadío andalusí, utilizando fundamentalmente metodologías derivadas de la arqueología extensiva, pero poniendo el acento sobre todo en cuestiones como la organización del territorio y las estructuras sociales que supuestamente podrían detectarse a través de ese análisis (por ejemplo: Bazzana, Cressier y Guichard, 1988; Cressier, 1995; 1996; Cressier y Osuna, 2005; Barceló et alii, 1996; Malpica, 1995a). Aunque hay importantes diferencias en los planteamientos de los diversos autores, estas orientaciones han permitido el desarrollo de una arqueología enraizada en el proceso histórico.

La arqueología extensiva ha proporcionado también un cuadro general de las estructuras físicas y la tecnología que sostuvieron el desarrollo y la expansión de dicho regadío. Los elementos que componen un circuito de regadío han sido progresivamente codificados: las captaciones de agua (manantiales, qanāt's), o los medios alternativos de derivar el agua de los arroyos, como las presas; la construcción de terrazas como elemento básico en la agricultura de montaña, las albercas para acumular el agua y garantizar el mantenimiento de un caudal, las conducciones y acequias como elementos para trasladar el agua, las norias y los molinos como elementos complementarios, etc. Pero las limitaciones del método, los objetivos que han guiado las investigaciones, unidos a la escasez de excavaciones suficientemente amplias, y la casi completa ausencia de análisis físico-químicos, y geológicos, así como la dificultad de obtener materiales susceptibles de aportar cronologías absolutas, unidos a la vaguedad con que las fuentes escritas árabes tratan estos temas, hacen que aún hoy nuestros conocimientos sobre la tecnología utilizada, y las modificaciones experimentadas en su aplicación a lo largo de los siglos, tengan un nivel muy general, y que con frecuencia se caiga en apriorismos. No obstante, la investigación arqueológica sigue proporcionando nuevos elementos que ayudan a completar este cuadro. Uno de esos elementos es la presa que estudiamos. Empezaremos por describir el contexto, la obra, y los datos arqueológicos existentes sobre la misma, de forma tan completa como sea posible. Para discutir después su cronología y funciones.

\section{SITUACIÓN}

Las sierras de Segura, Cazorla y Las Villas

El territorio entre las provincias de Jaén y Albacete está separado por un conjunto de macizos montañosos, cuya parte principal está integrada por las sierras de Segura y Cazorla (Fig. 1), donde nacen los ríos

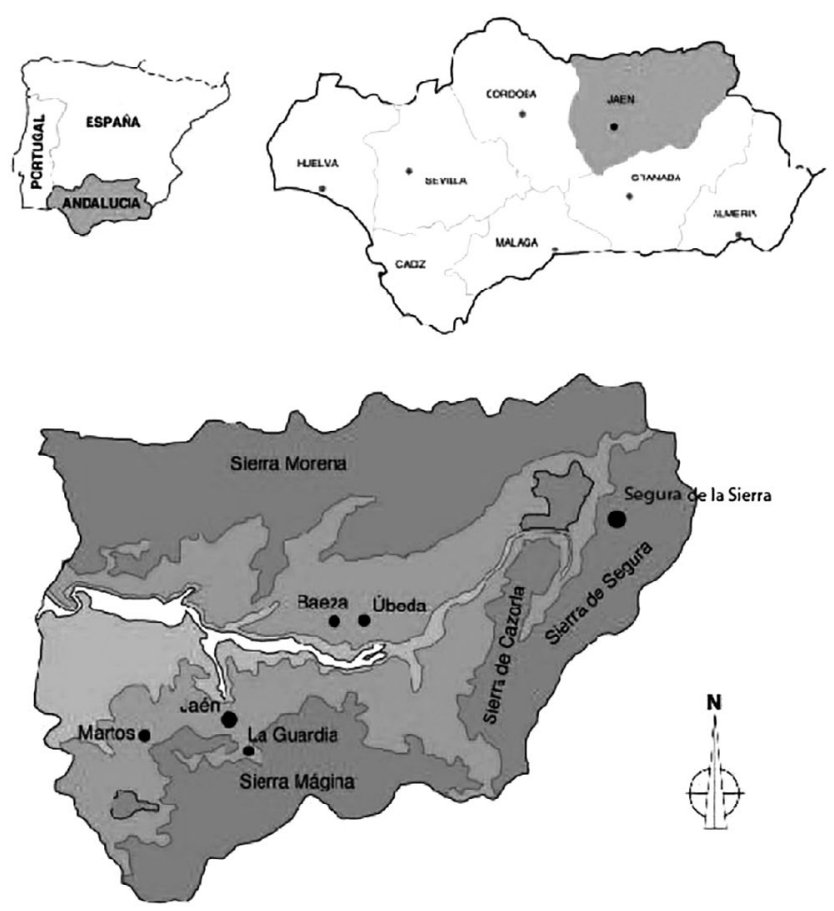

Figura 1: Planos generales de situación. 


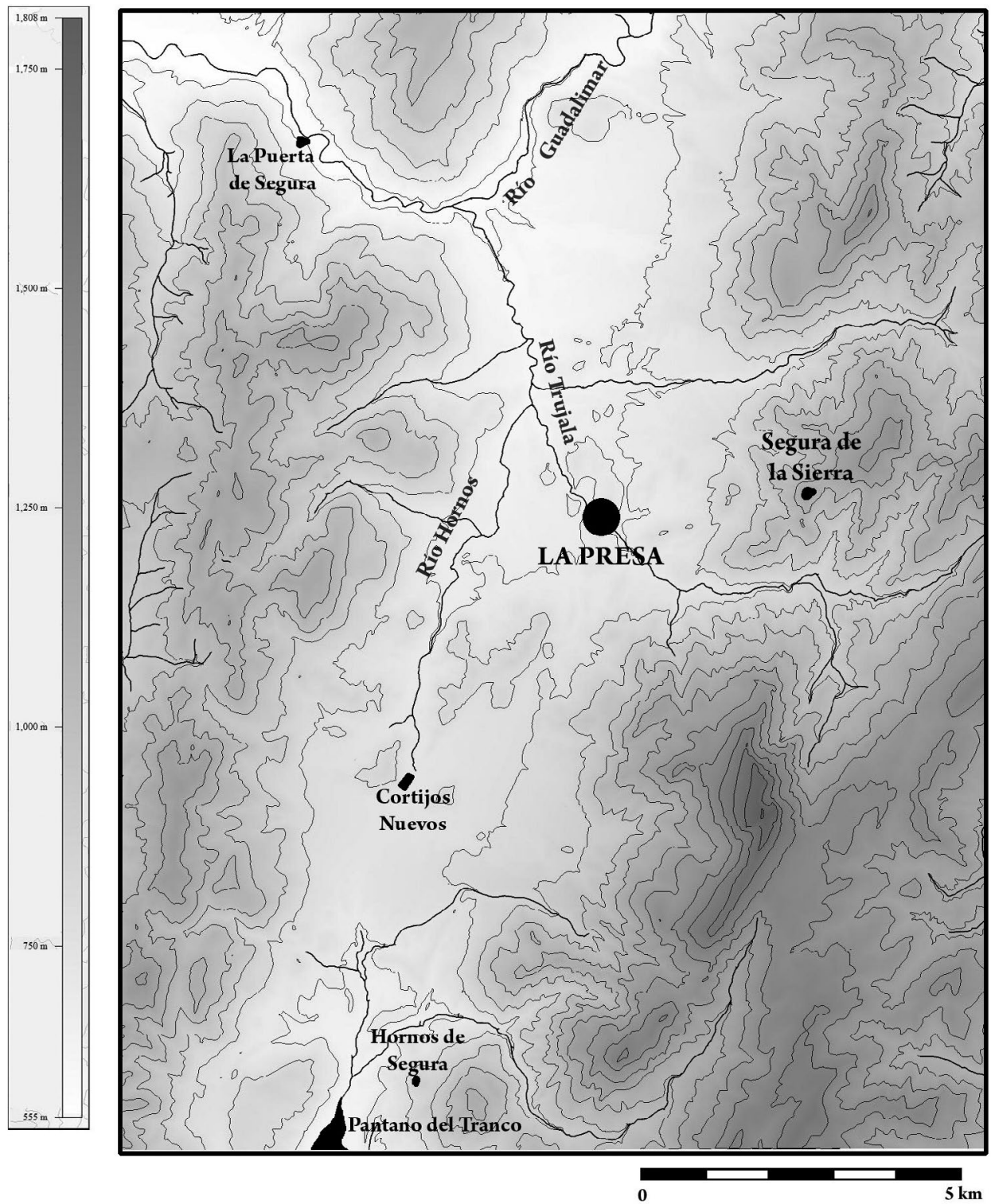

Figura 2: La Depresión del Tranco-Trujala.

Segura, que vierte hacia el este en el Mediterráneo (Guardamar de Segura, Alicante) y Guadalquivir, que lo hace hacia el oeste en el Atlántico (Sanlúcar de Barrameda, Cádiz).

El frente occidental de estas sierras presenta una pequeña depresión interior norte-sur. El tramo sur está recorrido por el río Guadalquivir, que circulaba con dirección norte-noroeste, aunque hoy ese sector está ocupado por el pantano de El Tranco. En el tramo norte, la red fluvial vierte hacia el Guadalimar (Fig. 2 ), con un primer sector recorrido por un numeroso conjunto de arroyos, nacidos de pequeñas fuentes, o generados en barrancos que recogen el agua de las lluvias y el deshielo, y que confluyen en el río Trujala, que ocupa el segundo sector del tramo. El Trujala nace en el interior de la sierra, por donde discurre su curso alto y medio, que se encaja profundamente en el terreno, bordea el lado sur del macizo donde se sitúa la localidad de Segura de la Sierra y, corriendo de este a oeste, recoge el agua de numerosos manantiales, pasando junto a la población de Trujala, antes de que el terreno se abra en el valle. Probablemente el nombre del río y de la población, derivan de trujal, término cuyo significado, según el diccionario de la RAE (1984), es «prensa donde se estrujan las uvas o se exprime la aceituna», o «molino de aceite». En el entorno de este río llegó a haber siete molinos durante la baja edad media y la época moderna. Tanto estos, como las huertas existentes en las laderas del río, recibían el agua no de este, sino de diversos manantiales, siendo aún hoy muy difícil el aprovechamiento del agua del Trujala en este tramo.

Al salir de la sierra, en el valle, con una altitud que oscila entre 600 y $750 \mathrm{~m}$, el río Trujala corre con dirección sur-norte, serpentea entre varias colinas, pasa por delante de Segura de la Sierra, recibe el agua de 
los ríos Hornos (izquierda) y Orcera (derecha), así como de otros arroyos, hasta desembocar en el río Guadalimar.

Durante casi dos décadas se ha estado investigando en el territorio de estas sierras (Salvatierra, 1998; 2001; Salvatierra et alii, 2001; Salvatierra et alii, 2006; Salvatierra y Visedo, 2008). En el curso de una serie de prospecciones en el valle del río Trujala efectuadas en 2005, algunas informaciones permitieron localizar una gran estructura, que se identificó como una presa, que por su técnica consideramos andalusí. No obstante su complejidad nos llevó a aplazar la publicación de la misma, hasta haber obtenido más datos.

\section{EL TERRITORIO DE SEGURA EN ÉPOCA ANDALUSÍ}

De este territorio no hay descripciones con cierto detalle hasta el siglo XII (Salvatierra et alii, 2006). Para esa época contamos sobre todo con dos autores. Del primero, al-Idrīsī, se sabe que inició su obra en 1138 , al trasladarse a Sicilia al servicio del rey Roger II y de su sucesor, para los que trabajó hasta su muerte en 1165. Su obra recogería, como era usual, la situación existente durante los siglos anteriores, aunque posiblemente fue actualizando sus informaciones con viajeros y comerciantes. De la sierra sólo cita las localidades de Segura, Quesada y Toya, (al-Idrīsī, 1989, 353, 354 y 388).

El segundo, al-Zuhrī, quizá llegó a conocer el territorio, dada la relativa amplitud de sus descripciones. De él sólo se sabe que vivía a mediados del siglo XII. De la sierra resalta que era un territorio muy poblado:

«La sierra de Segura est une grande zone montagneuse densément peuplée et mise en valeur, ou les récoltes, les troupeaux, l'arboriculture fruitière produisent en abondance. On y trouve des villages (qura), des ma'aqil (refuges perchés), des husun bien fortifiés, au nombre de 300 pour les qura et de 33 pour les husun. C'est dans la partie la plus haute de cette montagne qu'est située la ville (madina) de Segura, qui est l'une des villes les mieux protégées d'al-Andalus» (Guichard, 1990, 58)

Por lo que se refiere a la zona específica en la que se centra este estudio, cita a los ríos Guadalquivir y Guadalimar. En conexión con el primero menciona a Quesada (Qayšāta), Hornos (hiṣn Furnus) y según la descripción, en las proximidades de la actual presa del Tranco debía estar la mezquita del Alquezar (Masŷid al-Qașāra) topónimo que a su vez podría aludir a una presa sobre el río Guadalquivir. (Vallvé, 1986, 131, n. 195). Respecto al río Guadalimar dice:

«El Guadalimar nace a dos o tres cuerdas o medidas del nacimiento del río Mundo o Mesones y en este lugar coinciden el río de Murcia y el de Córdoba [Guadalquivir]. Después corre con poca agua hasta que recibe las aguas que salen de la Fuente de Beas? ('Ayn Bhy, o 'Ayn Bahiya o 'Ayn Mhyā o 'Ayn Samūra). Luego pasa delante de Segura, donde recibe otros arroyos. Aumenta su caudal y entra en el desfiladero llamado Halq al-Ayyil ('La Garganta del Ciervo'). Este desfiladero o maḍ̂iq lo cerró Abū Isḥāq ibn Hamušk, cuando era señor de Segura, con una perfecta obra de ingeniería, pues quiso con ello imitar el dique de Ma'rib en el Yemen. Convirtió aquella vega en un mar cuando subía el nivel del agua, sin tener ningún aliviadero, pues quiso que se desbordase (el pantano) por las cimas de aquellos montes, pero no le ayudó el lugar.

Y salía el río por la Garganta del Ciervo (Halq al-Ayyil) hasta llegar a Bujarcadin (Burŷy al-Qā La Torre del Cadí), conocida también por Burŷ̀ alA hmmar, 'La Torre Roja'. Allí desemboca en él el río Guadalmena ( $W \bar{a} d \overline{1}$ Armāna), que baja de la frontera de Alcaráz (al-Karas) y se convierte en un río caudaloso que se llama Guadalimar ( $W \bar{a} d \overline{1}-l-A h m a r=\mathrm{el}$ Río Rojo). Todas las aguas de la Sierra de Segura afluyen a este río.» (Vallvé, 1986, 130-131).

Este texto es el único entre las fuentes árabes que, por lo que sabemos, hace referencia a una presa, en esta zona. Pero presenta varios errores. En primer lugar, une los recorridos del río Guadalimar al que dedica las primeras líneas, y del río Trujala, al que corresponden la mención de que pasa por delante de Segura de la Sierra, y las referencias posteriores, retomando la descripción del Guadalimar a partir de la mención de que en él desemboca el Guadalmena. Otro error es la ubicación de Bujarcadin (Burŷy al-Qāậ = torre del Cadí) que el texto sitúa en la desembocadura del Guadalmena, donde no hay noticias de la misma, mientras que una torre con este nombre se localiza en sentido opuesto, en el Guadalquivir, aguas arriba de la actual presa del Tranco. La torre suele quedar sumergida cuando el pantano se llena. Este lugar debía quedar cerca de la mezquita del Alquezar (Masŷid al-Qașāra). Por tanto, no es posible hacer una identificación directa entre esa presa y la gran estructura localizada en el río Trujala, y en consecuencia es necesario un análisis detenido para llegar a alguna conclusión.

\section{LAS PRESAS EN AL-ANDALUS}

Una serie de trabajos han ido sistematizando los diversos tipos de presas, que hunden sus raíces en la antigüedad, y que serán empleadas abundantemente en época romana. Esa tradición fue retomada en Oriente por los árabes en los inicios de su imperio, conociéndose un buen número de presas construidas por las elites del califato omeya de Damasco (661-750). Se trata de grandes obras, construidas principalmente de mampostería y ladrillo, cuyo estudio ha sido recientemente revisado (Genéquand, 2013).

Hace tiempo que las investigaciones establecieron que, desde sus orígenes, existen dos tipos básicos de presa, la de derivación y la de almacenamiento. Las primeras suelen ser presas pequeñas y de materiales perecederos, que se reconstruyen con frecuencia. Las 


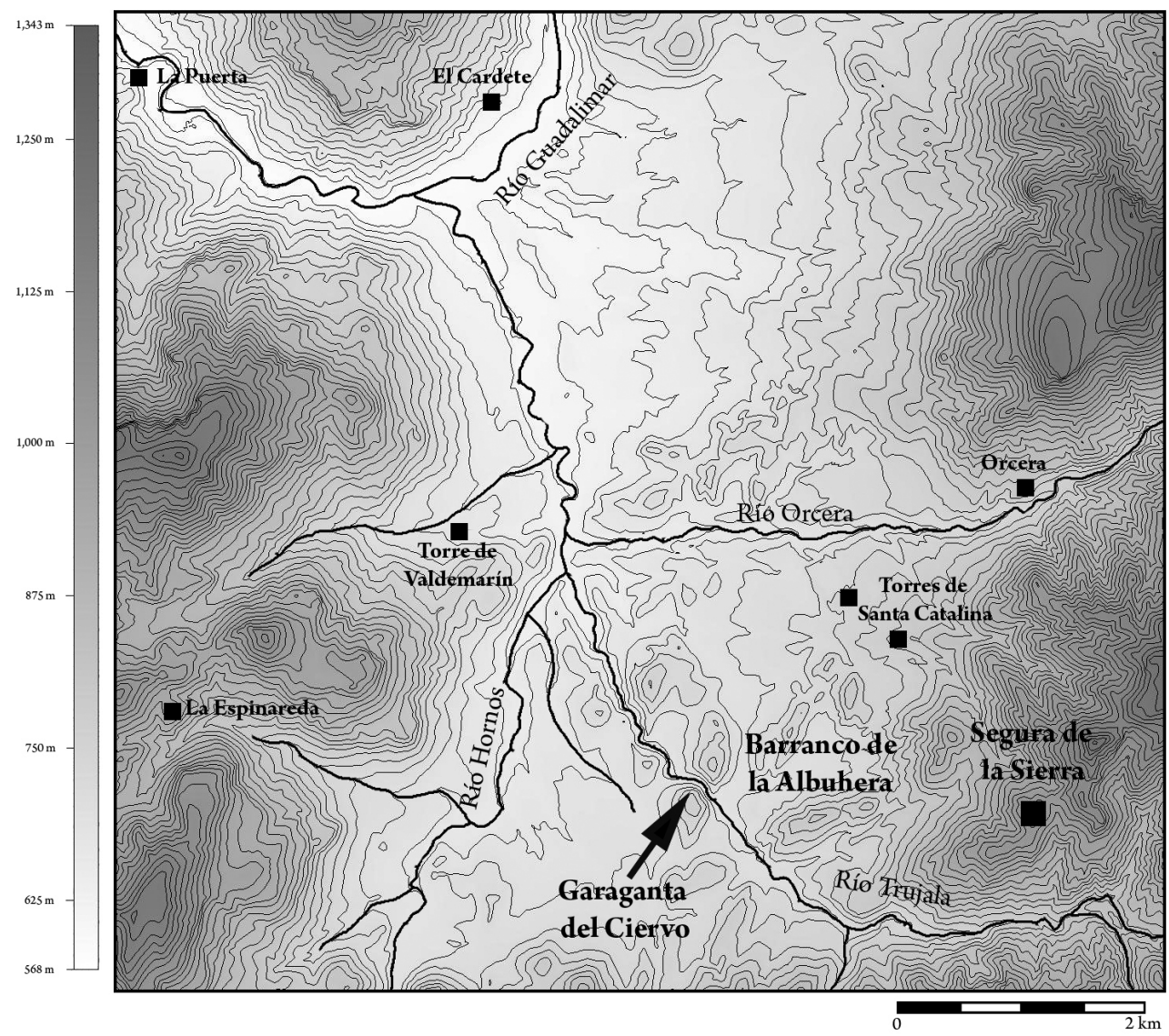

Figura 3: La presa y las torres del entorno.

segundas tienen por objeto el almacenaje de agua para su regulación y distribución. Estas pueden ser a su vez de dos tipos, la presa de peso (barrage-poids) y la presa de bóveda (barrage-voûte). Las primeras se caracterizan por el grosor del muro, existiendo una relación directa entre este y la capacidad de retención. Las presas de bóveda basan su capacidad de retención en la curvatura de su pantalla, que distribuye la presión del agua (Cressier y Osuna, 2005, 50-51).

En cuanto a la Península Ibérica, hasta los años 80, la investigación de las presas se hacía exclusivamente desde la ingeniería, con escasa atención a la cronología, y en un ambiente en el que dominaba la atribución a «los romanos» de todo tipo de obra, como por ejemplo la construcción de las existentes en la huerta de Valencia, lo que obliga a tomar las referencias con grandes precauciones (Fernández Ordóñez et alii, 1984). Las presas que se conservan que se pueden atribuir con seguridad a los romanos, estaban destinadas en general al abastecimiento urbano, siendo quizá una excepción, por su orientación al regadío, la presa de Almonacid de la Cuba, que además fue reutilizada en época andalusí (Laliena, Sesma y Utrilla, 1996). Por el contrario, no hay pruebas sólidas de que construyeran también pequeñas presas rurales para regadío. Hace ya unos años P. Cressier (1996) resumió los datos existentes sobre al-Andalus, profundizando en el posible origen de las tradiciones que se desarrollaron aquí, recopilando los datos existentes en las fuentes árabes sobre las presas de almacenaje, pero señalando que el problema principal es que ninguna de ellas había sido estudiada en profundidad. En la actualidad, a la serie recopilada por dicho autor, hay que agregar la del arroyo de La Jarilla, en Córdoba, una presa de almacenaje realizada con sillares, que quizá estuvo vinculada a la almunia de al-Rummānīy $a^{1}$, y donde podría encontrarse la convergencia entre las tradiciones omeyas orientales y las romanas locales. Hay menciones a otras presas, como la de Dalias (Cressier, 1986), y la de Turre (Cressier, 1996), ambas en Almería. Pero siguen faltando estudios en profundidad y desconocemos aspectos clave como su cronología, ya que algunas de ellas podrían ser muy posteriores.

\section{LA PRESA DEL RÍO TRUJALA}

Frente a la población de Segura de la Sierra, unos $5 \mathrm{~km}$ antes de la confluencia del río Trujala con el

1. Esta presa, probablemente del siglo X, fue localizada por J. L. Reyes, e incluida dentro del Plan Especial de Madinat alZahra, estando actualmente en estudio (Vallejo, 2010, fig. 4). Agradezco al descubridor y a los investigadores A. Vallejo e I. Montilla, los datos de esta presa y la visita a la misma. 


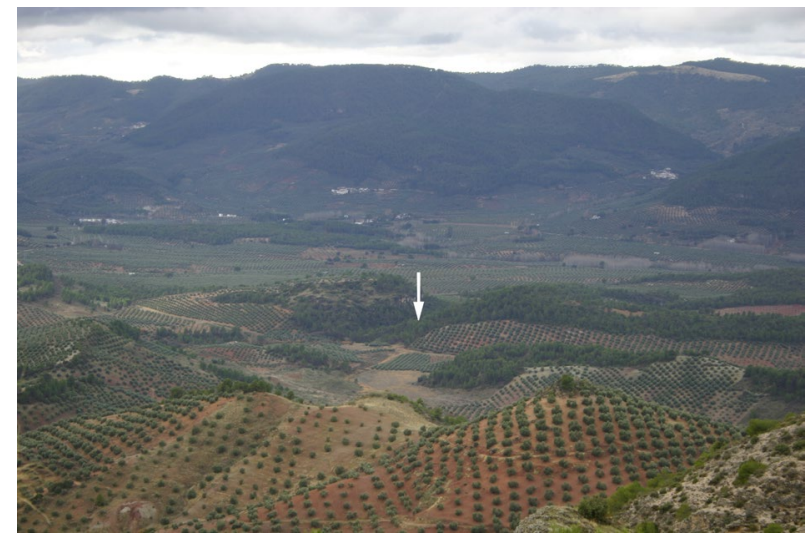

Figura 4: Ubicación de la presa desde Segura de la Sierra.

Guadalimar, el terreno tiene una altura media de unos $700 \mathrm{~m}$ sobre el nivel del mar, y el río pasa entre dos de las elevaciones principales del valle, de 772 y 774 $\mathrm{m}$ de altura respectivamente (Figs. 3 y 4). Ambas están separadas por un estrecho y sinuoso paso, de unos 300-400 m de longitud, labrado en parte por el propio río, cuyo lecho presenta, en el punto más estrecho, una anchura de unos $9 \mathrm{~m}$. Este fue cerrado por un potente muro, del que queda una parte (Fig. 5). El paso se abre en altura por la inclinación de las pendientes laterales, más acusada en el lado oeste. El muro conservado corresponde a este sector, apoyando su extremo en la roca, aprovechando la inclinación para fijarlo mejor al terreno (Fig. 6). Por el contario, en el lado derecho (este) la roca se presenta algo más vertical, y el estribo de este lado del muro se adosó a la misma, por lo que su adherencia era muy débil. Del mismo apenas queda nada. Esta presa era básicamente un 'tapón' en el cauce del río, que provocaría la acumulación de agua en su frente sureste, donde el terreno presenta un claro rehundimiento a modo de cubeta, que se refleja en las curvas de nivel de la planimetría moderna, y a simple vista en la distinta coloración del terreno.
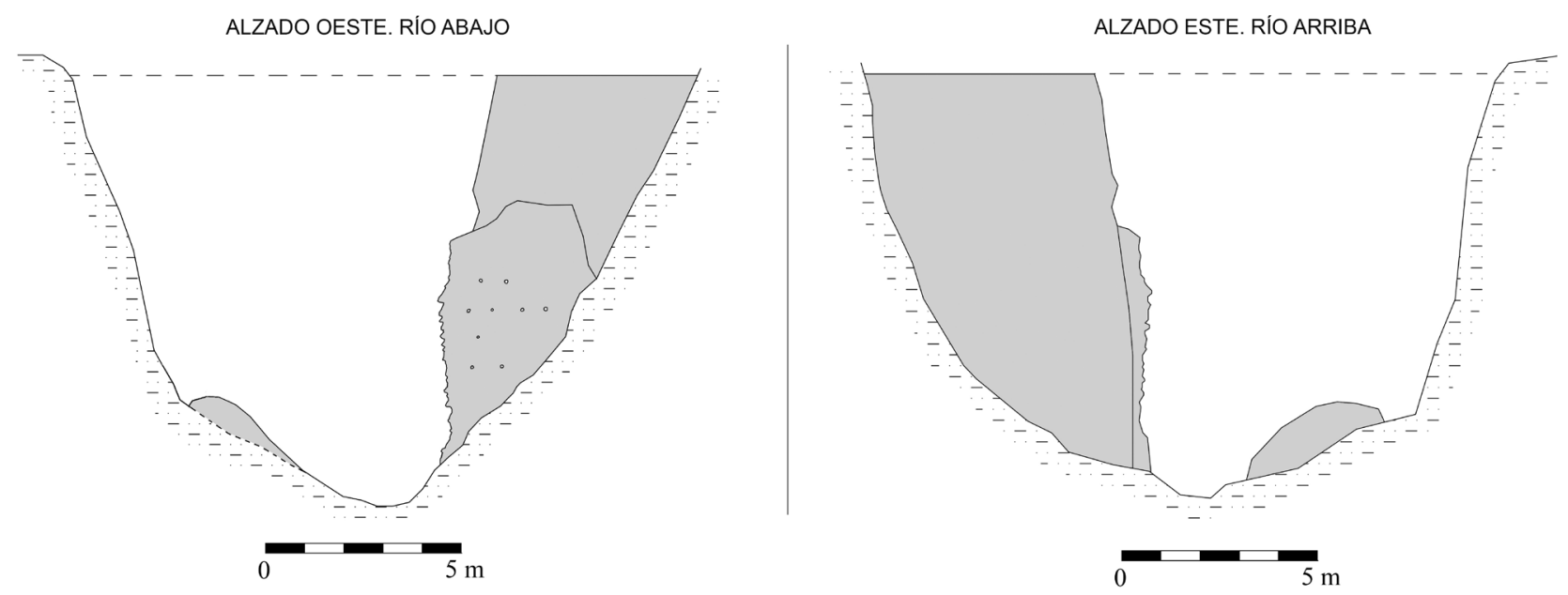

Sobre el término alfafer «existen en el levante peninsular varios topónimos que deben de estar relacionados con este. Así, en la provincia de Alicante se

Figura 5: La situación de la presa desde el este.

\section{LAS FUENTES ESCRITAS Y LA TOPONIMIA DEL ENTORNO}

Por lo que sabemos, hasta ahora esta estructura y su entorno no se habían identificado en las fuentes escritas posteriores a época andalusí, pero hay una referencia, hasta ahora un tanto oscura, que puede relacionarse con ella. En las Relaciones Topográficas de Felipe II, que recoge las respuestas a una encuesta general enviada por encargo de dicho rey a todas las poblaciones del reino de Castilla, hay una observación al final de la respuesta a la pregunta 56 , que es la que se refiere a edificios antiguos o ruinas que hubiese en dicho término de Segura, que puede hacer alusión a esta obra:

«... a media legua de Sigura a la parte de poniente ay otro edefyçio que se llama Alfafer que pareçe que alli se tomaba el rrio de Truxala para rregar y pesqueria es edefiçio antiguo de calycanto.» (Villegas y García, 1976, 230; Cebrián y Cano, 1992, 271).

Figura 6: Cortes de los alzados de la presa. 


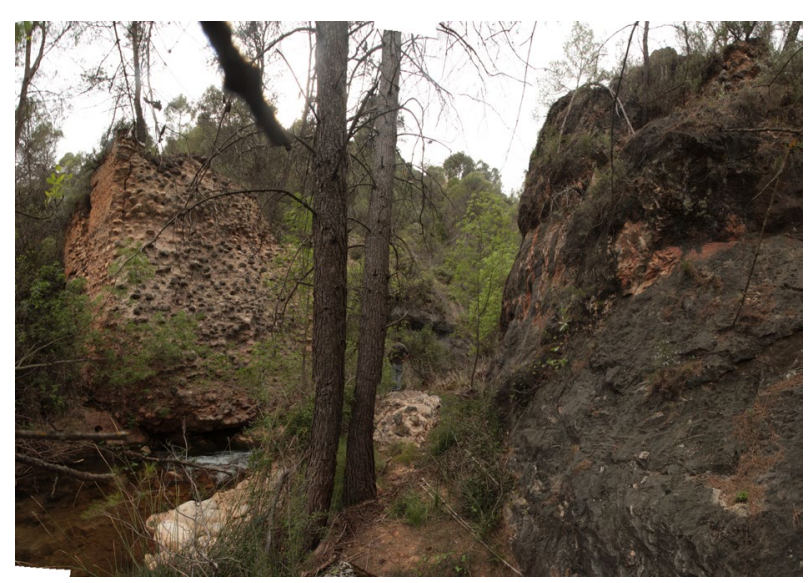

Figura 7: El tramo sur conservado de la presa.

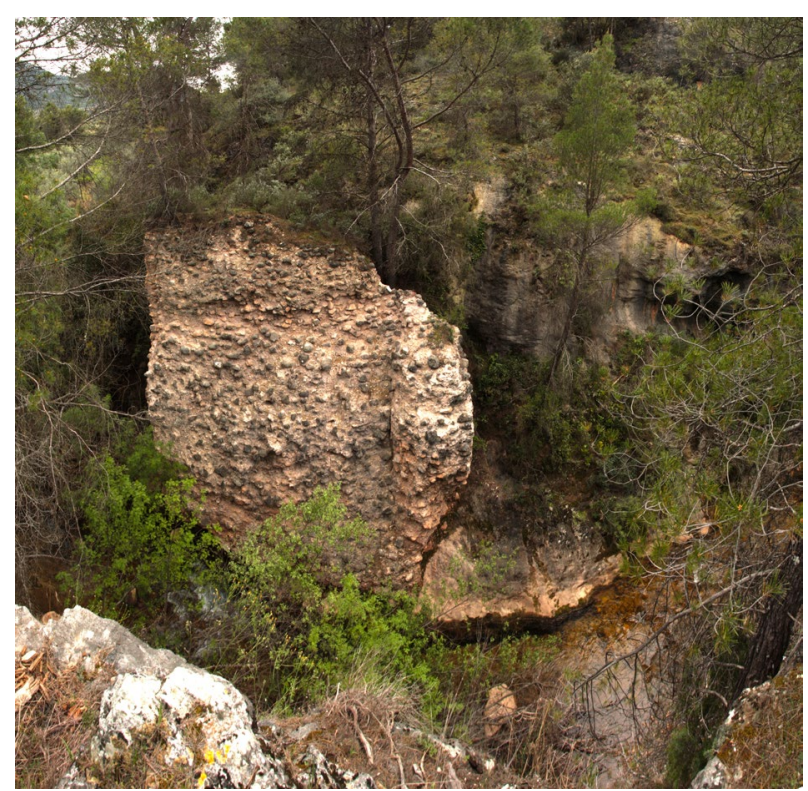

Figura 8: Frente del tramo sur conservado de la presa.

documentan Alfafar, Alfafara y L'Alfafara, todos ellos del árabe al-hafara, «el valle», así como Alfofra del árabe al-hufra, 'la hoya'. Y en la provincia de Valencia Alfafar / Alfafara (ant. Alfufar) y Alfofar, ambos del plural árabe al-hufar, 'las hoyas'. Todos estos topónimos proceden de nombres relacionados con accidentes del terreno, torrenteras, zonas profundas por las que discurre el agua, hoyas, depresiones, etc. (Barceló, 2010). La forma Alfafer parece responder a este tipo de topónimos, en la que además se ha producido el proceso de la imāla, que es la transformación en la pronunciación de /a/, sea breve o larga, acentuada o no, en /e/ o en /i/, así bāb > bib, madīna > medina, $k a b \bar{i} r>$ kibir (al-wādī l-kabìr $>$ Guadalquivir), banī $>$ beni, etc. $\rangle^{2}$.

2. Comunicación personal de $\mathrm{M}^{\mathrm{a}}$. A. Martínez Núñez, a quien agradezco la información, y su autorización parar reproducirla.
Ya en la época actual se identificaron los restos como una presa. En primer lugar, J. M ${ }^{\mathrm{a}}$. Almendral (1986) publicó algunos datos sobre la misma, con el nombre de Presa de Rihornos, por la aldea del mismo nombre situada relativamente próxima a la misma. El autor incluyó una fotografía, y un croquis del alzado y la sección, dando unas dimensiones de $21 \mathrm{~m}$ de longitud en el coronamiento y una altura de $11,40 \mathrm{~m}$, pero sin aportar datos históricos, fuera de identificarla como «árabe». Con posterioridad, P. Cressier se hizo eco de esta publicación, apuntando que podía tratarse de una presa de almacenaje (Cressier, 1996, n.40). Finalmente, algunos autores locales, como E. de la Cruz (1994) y M. Vigueras (2001) mencionan la presa y, aunque sugieren relacionarla con la citada por al-Zuhrī, ante las inexactitudes de la descripción vacilan en pronunciarse, y no llegan a analizarla en profundidad..

\section{LA CONSTRUCCIÓN Y SU TECNOLOGÍA}

En su origen, como señalaba J. M ${ }^{\mathrm{a}}$. Almendral, debía tener $21 \mathrm{~m}$ de longitud, auque ahora no nos ha sido posible medir lo que queda por la acusada pendiente y la espesa vegetación existente. En el frente que presenta junto al río tiene un grosor de $11 \mathrm{~m}$, y una altura conservada de 10,60 m. Esta última dimensión difiere ligeramente de las señaladas por J. Ma . Almendral a la que hemos hecho referencia, posiblemente resultado de la pérdida de masa, en altura.

A la hora de describir y valorar esta construcción es preciso distinguir entre lo que podemos considerar principios de ingeniería, y la técnica constructiva. Por lo que se refiere a la primera, cabe pensar que el constructor tenía conocimientos muy primarios, como pone de manifiesto el que en el lado derecho adosase la estructura al cortado de la roca, lo que sin duda la debilitaba. Técnicamente, el problema estaba resuelto en la época, solución que encontramos por ejemplo en recintos amurallados, y que consiste en el 'tallado' de la roca, bien en «escalera» o bien mediante «dientes», de forma que se proporcionaba mayor agarre a la estructura, sin embargo, aquí no se utilizó. Por otro lado, el deterioro que presenta aguas abajo, con grandes fragmentos desprendidos, apunta a que no estaba escalonada, o ataludada. Por otro lado, falta la pantalla que cerraba el río, por lo que no es posible saber si era un muro recto, o cóncavo, aunque su grosor apunta a lo primero. Todo ello hizo que la estructura resultase poco resistente a fuertes empujes, como los que podía provocar el agua torrencial en algunos momentos, lo que probablemente produjo su ruptura, habiendo continuado hasta el presente la pérdida progresiva del sector del muro que cerraba el río. Como consecuencia de todo ello sólo queda el lienzo construido en la margen izquierda (Figs. 7 y 8) y sólo parte del cimiento de la margen derecha.

Frente a los limitados conocimientos de ingeniería, la obra sí denota un profundo conocimiento del 
proceso de fabricación mediante tapiales. En este aspecto se trata de una obra notable. En apariencia, primero se construyó aguas abajo del río un muro, de unos 2 m de grosor (Fig. 9), en cuya cara externa aún pueden observarse los mechinales para agujas circulares de $10 \mathrm{~cm}$ de diámetro, teniendo los cajones unos $70 \mathrm{~cm}$ de altura. Aguas arriba debieron colocarse tapiales de madera, que fueron fijados mediante gruesos postes, clavados en hoyos abiertos en la roca del lecho del río, habiéndose identificado dos de ellos (Fig. 10). Entre estos hoyos, y el muro citado, se puede observar todo el corte interior de la presa, unos $9 \mathrm{~m}$. Se empleó una argamasa de extraordinaria dureza, y piedras de mediano y pequeño tamaño, lo que generalmente se denomina calicanto. El análisis realizado muestra que se empleó cal como elemento aglutinante y cuarzo y dolomitas como áridos. Llama la atención la falta de arcilla, que por lo general suele suponerse que era un elemento principal en la Edad Media, pero que aquí sólo aparece de forma residual. Inicialmente podía pensarse que la sustitución de la arcilla se habría producido por el tipo de obra, ya que ese material tiende a absorber agua y expandirse. Pero análisis en curso realizados en los castillos próximos de Vilchez y Giribaile, dentro de un radio de $100 \mathrm{~km}$, y fechados en época almohade, muestran una composición similar, lo que sugiere que se utilizaba el material más abundante en el entorno ${ }^{3}$.

Las medidas señaladas suponen un gran alarde técnico. Para levantar un muro con tableros de madera o 'tapiales', se colocaban estos en las dos caras del muro a construir, uniéndolos por su parte superior mediante vigas de madera o cuerdas. $\mathrm{O}$ mediante cuerdas se sujetaban a postes clavados en el interior. Otra opción podría ser en vez de emplear tapiales, la construcción de sendos muros de mampostería; en todos los casos se echarían después los elementos que componían la mezcla. Teniendo en cuenta lo que hemos indicado antes, aquí se empleó un método mixto, construyendo un muro aguas abajo, contrarrestando la mayor presión, y tableros aguas arriba. En cualquier caso la anchura provoca otros problemas, ya que al fraguar, la cal genera mucho calor, y una notable presión hacia el exterior, que debió ser difícil de contrarrestar. Por otra parte, la calidad de un muro depende de que el proceso de fraguado sea semejante en todo el volumen del mismo, obviamente el cálculo de la mezcla resulta más difícil cuanto mayor es el grosor de este, sobre todo con los medios de la época. De hecho, en el caso de las murallas se observa que si el muro que se pretendía construir era muy grueso, se adosaban sucesivamente los cuerpos necesarios,

3. El estudio de morteros de la presa lo efectuaron A. Sánchez, D.J. Parras y J.A. Tuñón, del Instituto Universitario de Investigación en Arqueología Ibérica (Universidad de Jaén). Los otros lo han sido en el marco del proyecto de Acción 8 (R6/8/2013): UJA2013/08/49.

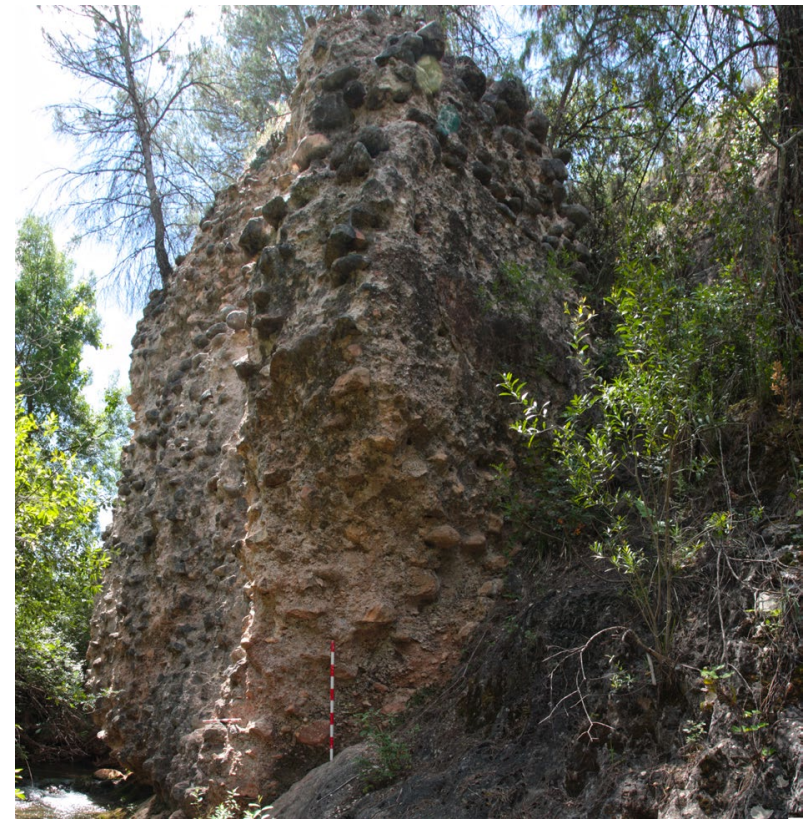

Figura 9: Detalle del muro límite de la presa aguas abajo.

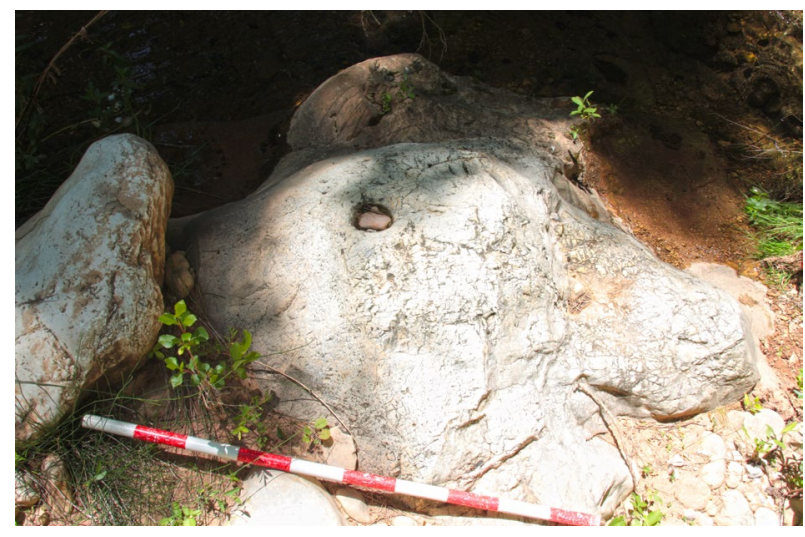

Figura 10: Hoyo de poste aguas arriba de la presa.

proceso que es perfectamente reconocible. Sin embargo nada de esto se aprecia en esta obra, por el contrario hay una notable regularidad en toda la anchura del mismo. De hecho, la cara interior del posible muro al que hemos hecho alusión, apenas se distingue del resto de la estructura. No obstante, de izquierda a derecha se aprecian tres sectores. El principal y más ancho en el centro. Aguas abajo se observa una larga grieta, que puede estar marcando el muro, pero que también puedo ser producto del deterioro. Río arriba, la cara exterior está compuesta por dos hiladas de mampostería revocada. Ello se aprecia claramente en la parte superior, donde existe una grieta entre este sector y el resto, que en consecuencia está igualmente en proceso de deterioro. Teniendo en cuenta la disposición vertical de las piedras de la hilada más exterior, ello supone que quizá la obra se hizo adosando dichas piedras a la cara interior del tapial, levantándola como un muro de mampostería, y echando después el resto de la argamasa en el interior. 
También por la necesidad de garantizar un fraguado adecuado, los edificios de gran altura se construían mediante fases de obra, de abajo a arriba, en tongadas o cajones que suelen tener entre $0,80 \mathrm{~m}$ y $1 \mathrm{~m}$ de altura, colocando y dejando fraguar el nivel inferior, levantando después los tableros para la siguiente fase. Este proceso hace que cada fase quede marcada tanto al exterior como al interior, donde puede observarse la línea de separación de cada momento, identificando cada una de las fases de obra. Esos elementos no se advierten en esta construcción. Las marcas exteriores pudieron borrarse recubriendo la obra de una capa de argamasa que las oculte, pero la inexistencia del límite de las tongadas interiores, que debían ser visibles en el frente roto, sólo se explica si la superficie superior de cada tongada se dejó con un perfil irregular de forma deliberada, cubriendo sólo en parte las piedras de la última capa, de forma que la primera del cajón siguiente terminase de cubrirlas, con ello posiblemente se conseguía mayor solidez, y no es posible ver las líneas de las fases de obra.

Finalmente, sí se aprecian algunos cambios que deben responder a criterios técnicos. En la parte inferior las piedras parecen tener mayor tamaño. En la superior las piedras son menores y más abundantes. Estos cambios no representan cronología, sino que deben considerarse sólo fases de obra, el menor tamaño de las piedras en la parte superior tendría como finalidad aligerar el peso.

En los cerros situados a ambos lados de la presa se aprecia la construcción de un antiguo camino. En la margen derecha este subía por el borde del río, donde se rompió la roca y alisó el terreno, con una mezcla de escalones irregulares y rampas poco marcadas, que llevan hasta la parte superior. En el lado izquierdo el camino se aleja del río, descendiendo suavemente, aunque siempre por encima de la cota del «pantano». Posiblemente podía cruzarse por encima de la presa, lo que permitiría cruzar el río y el pantano sin necesidad de dar un amplio rodeo.

\section{LOS ASENTAMIENTOS DEL ENTORNO}

Aunque en la actualidad el valle del Trujala está salpicado de pequeñas aldeas y cortijos, el estudio preliminar sobre los mismos no muestra indicios de que sean antiguos, por lo que a falta de estudios más detenidos cabe pensar que se trata de una repoblación de época moderna o más reciente. También las prospecciones (Salvatierra et alii, 2006), muestran que en época medieval, en la parte baja del valle, no había asentamientos, y tampoco se encuentran restos de ocupación en las colinas existentes dentro del mismo, lo que indica que estaba íntegramente dedicada a la agricultura. En él era posible un regadío limitado gracias a la red de arroyos a los que nos hemos referido. Los asentamientos principales se situaban en los laterales del valle, a gran altura, muy por encima de la cota irrigable. En época andalusí, al menos desde el siglo X, a la derecha del río Trujala, dominando todo el valle, estaba Segura de la Sierra, a $1.200 \mathrm{~m}$ de altitud, y en frente, a la izquierda (oeste) del río, el Castillo Catena (hoy La Espinareda), a $990 \mathrm{~m}$ de altitud. Por debajo de estos, en lo que puede considerarse un «escalón intermedio», sólo se localizan un conjunto de torres aisladas o rodeadas por una cerca. Al sur, relacionadas con los arroyos que conforman el río Hornos, se localizan las de Altamira y Gutamarta, mientras que al norte, en el entorno de la zona irrigada por la presa, pero por encima del nivel de esta, están las torres de Valdemarín, las tres de Sta. Catalina y la de Orcera.

\section{TORRE DE VALDEMARÍN}

A la izquierda (oeste) del río Trujala, cerca de Catena, en la ladera este del Cerro del Pavo, ligeramente por debajo de un manantial llamado Fuente del Águila, a unos $690 \mathrm{~m}$ de altitud se sitúa el cortijo de Valdemarín, aún habitado, que envuelve una gran torre por dos de sus lados. Realizada en tapial, con abundante piedra de mediano tamaño, tiene planta rectangular, y conserva dos pisos, aunque debió tener al menos uno más. Los castellanos introdujeron profundas modificaciones en los siglos XIV y XV, y algunas noticias orales se refieren a su utilización como ermita a principios del siglo XX, aunque luego volvería a su función de cortijo. Puesto que ni la torre, ni el conjunto de edificaciones adosadas han podido ser analizadas arqueológicamente, no es posible determinar si originalmente sólo existía la torre, lo que parece probable, o si ésta formaba parte de una aldea (qarya).

\section{Las torres de Sta. Catalina}

A la derecha (este) del río, entre los 730 y 780 m de altura, bastante por encima de la cota superior de la zona susceptible de ser regada por el río, se sitúan las llamadas torres de Sta. Catalina. Éstas son tres grandes torres, de unos $14 \mathrm{~m}$ de altura y plantas rectangulares, situadas a poca distancia entre sí, y que siempre han planteado el problema de su funcionalidad, ya que dada su posición, al pie de Segura de la Sierra, es obvio que no tenían función de vigilancia. Sin descartar que fueran torres residenciales, quizá estaban orientadas al almacenaje de la producción agrícola. Aunque generalmente se consideran como un grupo específico, posiblemente no eran muy diferentes a la de Valdemarín.

\section{TORRE DE ORCERA}

No se conoce en la actualidad ningún resto de fortificación en la localidad de Orcera, pero posiblemente en época almohade o inmediatamente después de la 
conquista debió construirse una torre, en torno a la cual se desarrollaría una cortijada, ya que esos son los elementos que el rey Sancho IV donó a la Orden de Santiago en 1285 (Chaves, 1975: 19). Por su parte, P. Porras (1997) indica que Orcera «tenía un cortijo con dos torres rodeado de un circuito». Desconocemos el texto preciso que utilizó B. Chaves, por tanto es posible que ambos autores estén utilizando el mismo, y que el primero no nos ofrezca la referencia completa, o que sean distintos, y que estén mostrando una evolución de la población.

Estas torres las hemos fechado entre los siglos XII-XIII, considerándolas en su mayoría almohades (Salvatierra et alii, 2006), y por tanto, levantadas cuando ocuparon el territorio tras la sumisión de Ibn Hamušk en 1169 (Aguirre y Jiménez, 1979), Y posiblemente antes o poco después de la batalla de Las Navas de Tolosa (1212), debido a que en el entorno de algunas de ellas se ha recogido material de ese periodo. Pero sin descartar que algunas puedan ser ya castellanas, configurando el primer paso en el proceso de colonización del valle por la Orden de Santiago tras la conquista.

\section{LA PRESA DE LA GARGANTA DEL CIERVO.}

Analizados los precedentes, y revisada la documentación escrita, arquitectónica y arqueológica, se trata ahora de establecer si la presa localizada en el río Trujala pudo ser realmente la citada por al-Zuhrī, y cual fue su objetivo y funcionamiento.

\section{AUTOR, CRONOLOGÍA Y CONTEXTO HISTÓRICO}

Como hemos dicho, al-Zuhrī es la única fuente que menciona una presa en la zona, que habría sido construida por Abū Isḥāq b. Hamušk, personaje al que se califica de señor de Segura. A pesar de los errores del texto en otros aspectos, es muy verosímil que este sea correcto. El problema es que en base a la estructura de los nombres árabes, el mismo resulta poco clarificador (Manzano, 1992). Para los no familiarizados con estos nombres, conviene recodar que se componen de la kunya, apelativo o título honorífico, eso es precisamente Abū Ishạāq, que sólo indica que el personaje que designa es el «padre de Ishāà». A continuación el nombre personal (ism), que aquí no aparece. Y el $n a-$ $s a b$ que indica la filiación en línea paterna, usándose la partícula $i b n$ (que puede abreviarse como $b$.) y que indica que el personaje es «hijo de». El nasab puede incluir a los antepasados inmediatos, o indicar solo a algunos ascendientes. Por tanto, tal y como está escrito, se nos indica que el constructor fue el padre de Ishạaq e hijo, o descendiente, de Hamušk. Este último nombre parece ser un apodo que, según Gaspar y Remiro (1980) aludiría a Amusco, localidad palentina de la que procedería el fundador del linaje. Esto supone que en teoría pudo haber varias personas con los mismos elementos en el nombre, y con cronologías diversas. Pero, afortunadamente, la mayoría de los datos parecen apuntar a un mismo personaje.

El que la mayoría de los autores denominan señor de Segura era Ibrāhīm b. Hamušk (Aguirre y Jiménez, 1979). Gaspar y Remiro trazó una historia de este personaje, desde un hipotético origen de su familia en Amusco, Palencia, a la corte de los b. Hūd de Zaragoza, oscilando luego entre la obediencia a los almorávides y a Alfonso VII, pero sin precisar las fuentes que emplea para cada afirmación (1980,187-188). Finalmente se afincaría en Valencia, donde se convertiría en el lugarteniente de Ibn Mardanīš. Cuando este último llegó al poder en Murcia en 1147, Ibn Hamušk ocupó hiṣn Šaqūbus (Sócovos de Yeste) y Segura de la Sierra. Tras la retirada de Alfonso VII de Úbeda y Baeza ante el empuje almohade (1157), ambos hombres atacaron a estos. Los almohades se retiraron ocupados en su expansión por el Magreb, e Ibn Mardanīš e Ibn Hamušk ocuparían el territorio de Jaén (1159), creándose un reino donde ejercería el poder este último, llegando a atacar Córdoba y Granada, aunque sin resultado. La reanudación de la ofensiva almohade le llevó finalmente a someterse en 1169 y fue confirmado en el gobierno de Jaén hasta 1176, en que se trasladó a Mequinez, muriendo poco después.

Pues bien, después de que este se sometiese a los almohades, Ibn Șāhib al-Șālat (1969) lo cita como Abū Ishāq Ibrāhīm b. Hamušk en al menos dos ocasiones (1969, 148, 214). Por tanto parece clara la identificación entre el conocido aliado de Ibn Mardanīš y el constructor de la presa, obra que por tanto se realizaría muy probablemente entre 1147 y 1169.

A parte de ello, hay al menos dos autores que prolongan el nasab de Ibrāhīm. Ibn al-Ațīr, según una cita A. Huici (2000), se refiere a «Ibrāhīm ibn Ahmed ibn Mofrid ibn Hemochk». Por su parte Ibn al-Jatīb se refiere a «Ibrāhīm Ibn Muhammad ibn Mofarrech ibn Hamusko», según una referencia recogida por Gaspar y Remiro. Las variantes en el primer caso (Ahmed, o Muhammad) pueden deberse a errores en las fuentes que manejaron los autores árabes, en el segundo puede deberse a las distintas formas de transcribir los nombres árabes al castellano antes de la formalización que hizo la escuela de Estudios Árabes a mediados del siglo XX.

Por otro lado, A. Huici localizó en otras fuentes otros dos personajes con el nasab terminado en Hamušk. El primero es un andalusí llamado «'Abd Allāh ibn Hamsk», según la vocalización de uno de los manuscritos que manejó. El mismo sirvió en el ejército del califa almorávide 'Ali ibn Yūsuf y se distinguió durante el cerco al que los almohades sometieron a Marraquech en 1130 (Huici, 2000, 81-82 y 239, n 1-2). A. Huici se inclina a pensar que debe relacionarse también con Ibrāhīm ibn Hamušk, ya que por las fechas pudo ser el mismo personaje. Por otro lado, en su traducción de la obra de al-Marrākuš̄i (1955) se refiere 
a otro individuo que este cita en los años cuarenta, en el contexto del final del poder almorávide:

«Se apoderó de Jaén y sus distritos hasta el castillo de Segura y lo contiguo a aquella frontera un hombre llamado 'Abd Allāh; el nombre de su padre no lo conozco. Es el que llaman entre ellos Ibn Hamušk y quizá se apoderó este 'Abd Allāh de Córdoba por unos pocos días»».

El problema es que en esos años Jaén estuvo primero en manos de Sayf al-Dawla (1145), luego fue ocupada por los almohades, que en 1148 la entregaron a Ibn Gāniya (Aguirre y Jiménez, 1979, 121, n. 637). Simultáneamente, a partir de 1147, Alfonso VII ocupaba Úbeda y Baeza, cortando la comunicación entre Segura de la Sierra y Jaén. En consecuencia es difícil situar cronológicamente esas conquistas. Y de hecho el propio A. Huici no recoge este pasaje en su monumental obra sobre los almohades. Es posible que el episodio referido por al-Marrākušñ corresponda en realidad a la conquista llevada a cabo por 'Abd Allāh ibn Mardanīš e Ibrāhīm Ibn Hamušk a partir de 1159, y por tanto todo, incluido el nombre de 'Abd Allāh, sería sólo una confusión, incluso quizá al-Marrākušī mezcló los nombres de ambos aliados, convirtiéndolos en un sólo individuo. No obstante, las dos menciones a 'Abd Allāh obligan a no descartar la posibilidad de que también fuera parte del nasab de Ibn Hamušk.

\section{OTRAS OBRAS DE IBN HAMUŠK}

A parte de esta presa, en los últimos años hemos atribuido a Ibn Hamušk una serie de edificios, levantados quizá emulando a los que al parecer construía Ibn Mardan̄̄š en Murcia. Estas construcciones servirían en parte para reforzar su control sobre el territorio, y en parte como elementos propagandísticos frente a los almohades.

Entre las obras más probables están las llevadas a cabo en Segura de la Sierra, donde se construyó un auténtico alcázar, en la cima del cerro en el que se asienta la población. Este alcázar estaba dotado de una muralla, de la que sólo quedan algunos restos, que hoy están enterrados (Salvatierra et alii, 2001). La estructura de la misma presenta notables diferencias con todas las demás murallas estudiadas hasta ahora en el territorio del Alto Guadalquivir. Formando parte de esta muralla, constituyendo una gran torre rectangular, levantó un pequeño baño, del que aún queda parte de la sala templada con su hipocausto, y algunos restos de las demás, pero muy modificado por las sucesivas «restauraciones» emprendidas desde los años sesenta. El baño estaba decorado con atauriques y pinturas naturalistas, de estas últimas se ha recuperado un fragmento con representación de palmeras, elementos ajenos a las decoraciones almohades. Así mismo este recinto habría contado con un pequeño palacio, que debió ser destruido y cuyos restos sirvieron para compensar el desnivel existente en el lado norte, cuando los santiaguistas ampliaron el recinto.

En el territorio inmediato pudo levantar algunas de las fortificaciones existentes, en especial el castillo que al parecer estuvo situado en Peña Hamusgo, según las Relaciones de Felipe II (Villegas y Serrano, 1976, 229) cuyo topónimo parece aludir claramente a Ibn Hamušk.

Quizá también se deba en parte a Ibn Hamušk la construcción del palacio ubicado en el alcázar del Cerro de Santa Catalina en Jaén, del que proceden restos de una espléndida yesería, que adornaba el paso entre dos estancias, y que presenta elementos mezclados de las tradiciones andalusí y almohade, incluyendo entre estas últimas la inscripción que la corona (Martínez Nuñez, 2002).

\section{LA FUNCIONALIDAD}

En principio, la presa podía tener dos objetivos, por un lado, hay que suponer que el principal, era generar un amplio circuito de regadío. Por otro, era posiblemente un elemento propagandístico, que debía mostrar el poder de su constructor, frente al avance de los almohades.

¿Cómo funcionaba la presa? Delante de la zona donde se construyó (lado este), el terreno está rehundido, con lo que tiende a crearse de forma natural una amplia zona encharcada. Aún en la actualidad numerosos habitantes de Segura de la Sierra coinciden en denominar a esa zona pantano del rodero porque hasta hace pocos años solía acumularse en determinadas épocas del año una lámina de agua. En la cartografía oficial de España (plano 1:50.000) figura el barranco de la albuhera, que desembocaba en este «pantano». Dicho topónimo se registra ya en la cartografía de principios del siglo XX. Este término es una variante de albufera, término procedente del árabe y cuyo significado en castellano ya lo reflejaba el léxico compuesto en el siglo XVI por Diego de Guadix (2007, 49), según el cual el término procede de al-y Buhayra que significaba 'mareta o marezilla' diminutivo de bahar que significa 'mar'. Por lo que Albuhayra significaría 'la mareta o la marezilla, la mar pequeña', designando cualquier lago o congregación de agua. Del mismo término lo deriva C. Barceló $(2010,56)$. Es decir implicaría que el agua que discurriría por dicho barranco desaguaría en una albufera o laguna. En principio el agua acumulada aquí, de forma natural, probablemente no tenía una vía de salida, fuera de la filtración y la evaporación.

La presa provocó un aumento considerable del agua acumulada en esa zona. Según los cálculos efectuados, teniendo en cuenta la topografía actual, el agua tenía que subir unos 2 metros antes de encontrar su salida natural, que se encuentra situada al pie de la colina del lado derecho (norte). Esa acumulación hacía, por otro lado, que la zona lagunar llegase a cubrir 


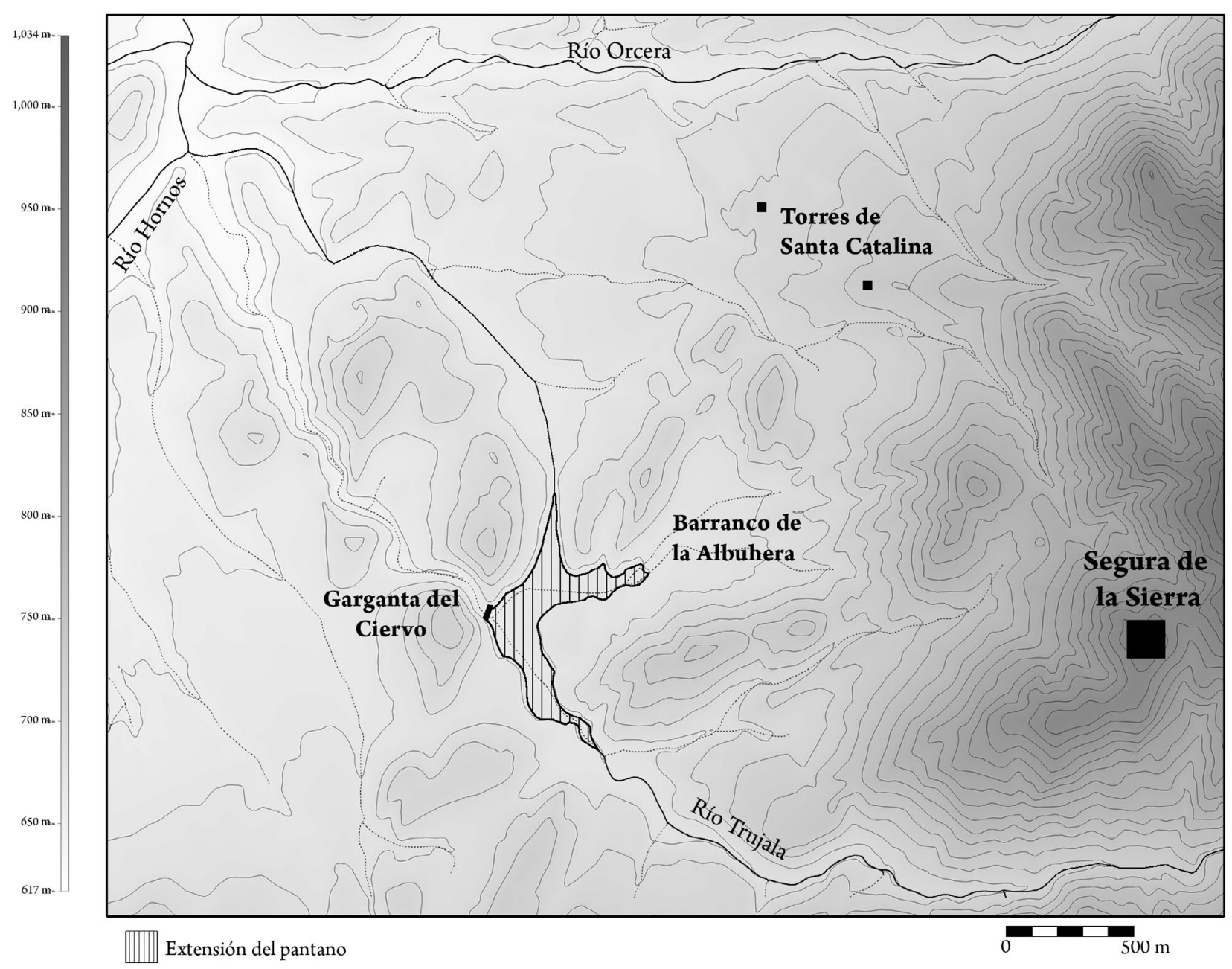

Figura 11: Extensión del pantano.

aproximadamente unas 18,8 ha, algo más de lo calculado en su día por J $\mathrm{M}^{\mathrm{a}}$. Almendral (Fig. 11).

En función de los criterios resumidos más arriba, y dado que para que funcionase hacía falta el almacenamiento de gran cantidad de agua, cabe considerarla de almacenaje. Pero ello presenta algunos problemas. Es cierto que se creó un gigantesco depósito y, en este sentido, el término Albuhayra alude también a grandes albercas artificiales, como la Buhayra de Sevilla o al-Rumaniyya en Córdoba. Pero estos depósitos tenían aliviaderos, ligados a conducciones, situados generalmente en la parte inferior, como se ha demostrado en el último caso, donde el agua se aprovechaba para regar las extensas terrazas situadas por debajo de la almunia (Arnold et alii, 2008). Si no existieran estos, sólo estando el depósito lleno sería posible extraer agua para el riego. Sí, como afirmaba al-Zuhrī, la del Trujala no tenía aliviaderos, el agua sólo podía salir por el punto que hemos señalado. Naturalmente, dados los errores del texto de al-Zuhrī, no es posible confiar plenamente en esta afirmación. Pero el análisis combinado de prospección arqueológica y análisis topográfico de todo el perímetro, confirma que el que se encuentra a menor altura es el ya mencionado. Tampoco se aprecian inicialmente zonas en las que pudieran haber habido hipotéticas salidas que hubiesen quedado taponadas con el paso del tiempo. Es igualmente difícil considerarla de derivación, ya que sin el almacenaje, aparentemente no podía funcionar.

Por tanto esta presa no encaja exactamente en ninguno de los tipos que hemos visto más arriba. Pero P. Cressier, subrayaba la complejidad de cualquier clasificación, debido a las prácticas tradicionales, y constataba una serie de variantes, señalando: «Il existe des cas intermédiaires, où, sans être un barrage de retenue au sens strict, le barrage de dérivation, fermant le cours d'eau, permet l'élévation du niveau de celle-ci en amont et donc une extension des zones potentiellement cultivables.»(Cressier, 1996, 145). En apariencia esa descripción se adapta a la presa que estudiamos. Es interesante observar que, como señala el propio P. Cressier (1996, 148), la presa de Mārib era en cierta forma de este tipo, en cuanto a su función. Aunque por supuesto, la sofisticación del sistema hidráulico era muy diferente.

Como decíamos más arriba, el principal objetivo de la presa pudo ser el regadío. Si analizamos el río Trujala parece evidente que aguas arriba no podía tomarse 


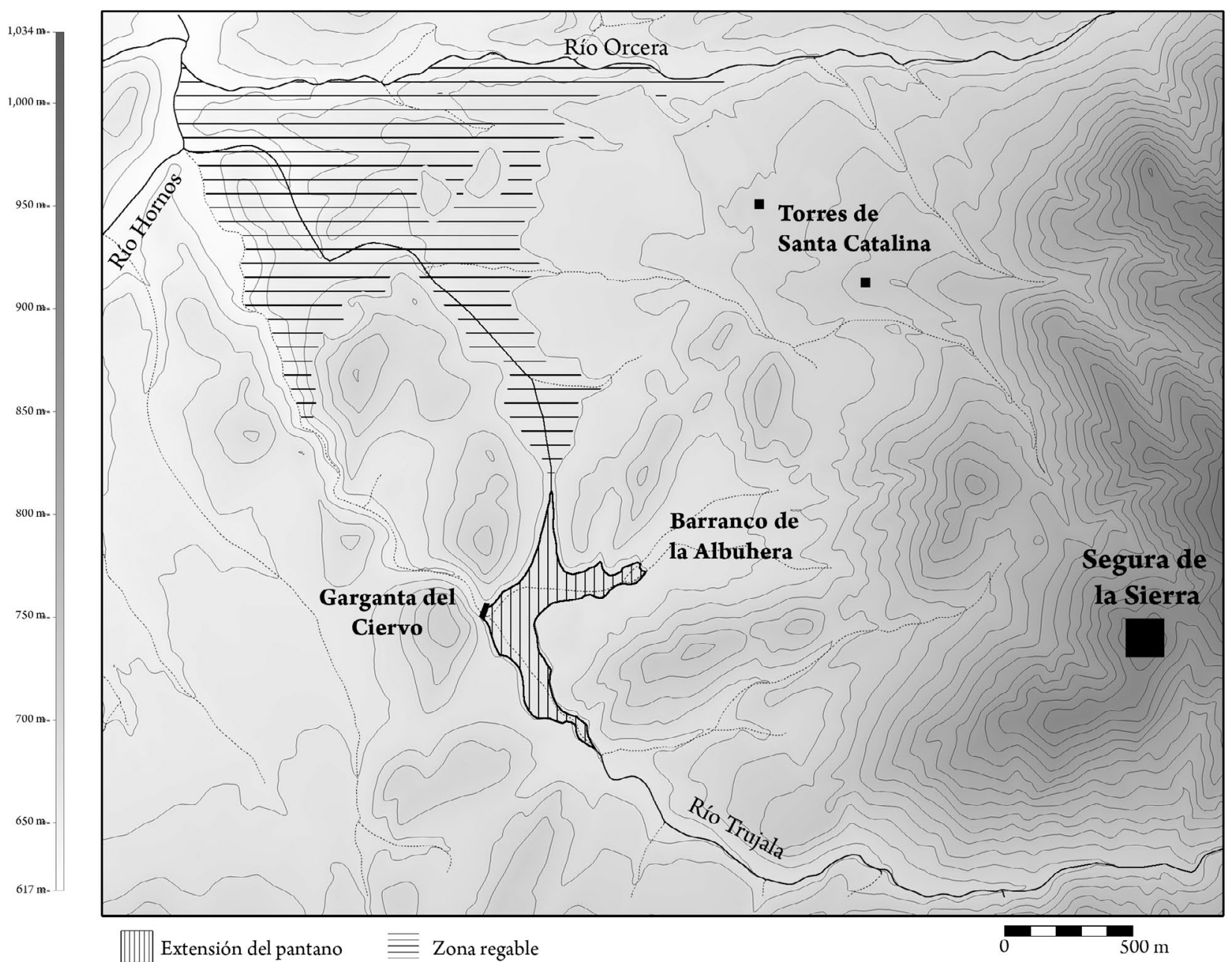

Figura 12: La zona regable por el pantano.

agua para regadío, ya que el cauce está profundamente encajado en el terreno desde su nacimiento, terreno que además es extraordinariamente abrupto. De hecho, como hemos indicado, las huertas que existen en la zona, y sobre todo los molinos que funcionaron en el pasado, recibieron el agua de otros manantiales.

El agua que salía del «pantano» debía circular en paralelo al antiguo cauce del río Trujala, pero a mayor altura que aquel, al este de una serie de colinas y pequeñas alturas a cuyo pie, en el lado oeste, discurría aquel, que el río recuperó tras la ruptura de la presa. En superficie no se observan acequias u otro tipo de conducciones, pero no podemos descartar que ésta se encuentre a mucha más profundidad de lo que hoy vemos, y que el terreno se haya colmatado, algo verosímil por su posición al pie del cerro. Por otra parte, la fotografía aérea del llamado «vuelo americano» de 1956 muestra algunos elementos enterrados -como una posible alberca- que sería interesante investigar para aclarar su función. Estas incógnitas sólo podrían aclararse mediante las excavaciones arqueológicas. Entre ese hipotético cauce y el río Trujala queda una amplia zona que sólo recibe agua procedente de arroyos estacionales, por tanto la presa permitiría proporcionar a esa zona un caudal mayor, y con un régimen más continuo (Fig. 12). La zona máxima teóricamente irrigable sería de unas 135 hectáreas, extensión de tierra delimitada por el antiguo cauce del río Trujala y el río Orcera, que también queda por debajo de la cota de desagüe.

Por su posición y cronología, resulta inevitable especular con la vinculación de algunas de las torres descritas más arriba, con la zona irrigada por la presa, aunque existe un pequeño desajuste temporal. Para que presa y torres hubiesen coincidido en el tiempo sería necesario a) que la presa hubiese estado en funcionamiento más allá de la desaparición de su constructor, b) que la atribución de la presa a Ibn Hamušk sea un error más de al-Zuhrī y que la obra sea en realidad algo posterior, o c) que las torres sean anteriores a Ibn Hamusk, o como mínimo que se levantaran también durante el reinado de este, quizá formando parte del mismo proyecto. El que al-Zuhrī no aluda a ellas no tiene un significado particular, ya que tampoco alude a otras de las obras que aquel levantó en la propia Segura. Hay que admitir que el hecho de que las torres tuvieran sobre todo funciones residenciales y agrícolas, y que se encuentren fuera (Valdemarín) o por encima, 
del espacio irrigado por la presa, induce a vincularlas. Pero sin excavaciones que establezcan con seguridad su cronología, no será posible aclarar definitivamente esta cuestión.

\section{¿UNA INNOVACIÓN TECNOLÓGICA?}

El elemento básico para construir un perímetro irrigado andalusí es obviamente el agua circulante, que se podía obtener de numerosas formas, como por ejemplo construyendo la conducción junto a un acuífero, o con una noria tomando el agua de un río o de un pozo y depositándola en una conducción, o mediante una presa colocada en un río.

Si comparamos los efectos de la presa construida por Abū Isḥāq Ibrāhīm b. Hamušk con los sistemas basados en las presas descritas, hay que concluir que los principios y la teoría eran los mismos, pero puesto que las necesidades eran distintas se trató de adaptar una tecnología -la de las murallas de tapial- aparentemente sin tener en cuenta los problemas generados por esa nueva función, ya que si bien es posible que pudiera resistir el agua embalsada, como lo hacen las grandes albercas, y que el agua pudiera pasar por encima, como en las presas de derivación «normales», obviamente no se tuvo en cuenta la presión que podía ejercer el agua en movimiento de un arroyo de carácter irregular y torrencial, y que acabaría provocando su destrucción.

Otra cuestión es si tenía sentido dicha construcción, es decir, si la relación coste/esfuerzo quedaba compensada por los beneficios en forma de aumento de la superficie regable, algo que parece como mínimo discutible, ya que esta parece que pudo ser como máximo de unas 135 ha. Es posible, por tanto, que otro de los objetivos, quizá incluso más importante, fuera la propaganda. Como hemos visto, al-Zuhrī afirma, según la traducción de J. Vallvé (1986), que Ibn Hamušk, quiso con ello imitar el dique de Ma'rib en el Yemen. Convirtió aquella vega en un mar cuando subía el nivel del agua, sin tener ningún aliviadero, pues quiso que se desbordase (el pantano) por las cimas de aquellos montes, pero no le ayudó el lugar. Efectivamente, esto último no resultaba posible por la propia topografía del espacio, por lo que es posible que esa afirmación fuera en parte sólo una figura literaria, al igual que la alusión a la presa de Mărib, pero como hemos visto, existen algunos puntos de contacto con la famosa presa yemení (Hehmeyer y Schmidt, 1991; Cressier, 1996; Darles et alii, 2013). Otra cosa, es que el hundimiento de la presa, convirtiera en baldío ese esfuerzo.

\section{EL FIN DE LA PRESA}

No sabemos con seguridad cuando se rompió la presa. La referencia de al-Zuhrī a que no le ayudó el lugar puede interpretarse de dos formas. La primera, con un sentido más literal, en que no consiguió que el agua se desbordase por encima de las colinas, aunque funcionó durante un periodo desconocido, lo que vendría confirmado por el hecho de que en época de Felipe II aún podía retener agua. Pero como hemos expuesto, esto parece más una figura literaria que un objetivo real. La segunda interpretación, es que la presa cedió, perdiendo su funcionalidad al poco tiempo de estar terminada, incluso durante el reinado del citado Ibn Hamušk.

La ruptura de la presa debió producirse porque la acumulación de agua supuso una notable presión, aunque es mucho más probable que la ruptura se produjese por una crecida repentina del río, algo normal en ríos de montaña, y que además pueden llegar a arrastrar materiales como troncos de árboles, que pueden golpear con fuerza los obstáculos que encuentren en su camino, como aún hoy sucede con los puentes en algunos ríos. Tampoco cabría descartar que un fuerte deshielo produjese una acumulación excesiva de agua, que no pudiera ser evacuada con la suficiente rapidez, aumentando la presión. En cualquier caso, el lado derecho (norte) cedió, y el agua se abrió paso hacia el antiguo cauce. Desde entonces esa ruptura ha ido ampliándose, y partes del lienzo se encuentran caídos en la ribera y en parte han sido arrastrados por el río, en cuyo cauce aún se localizan algunos fragmentos de gran tamaño.

\section{CONCLUSIONES}

Creemos haber resuelto satisfactoriamente algunos de los problemas que inicialmente nos planteaba la presa, como es su caracterización, su identificación con las referencias escritas, la de su autor y cronología inicial y su funcionalidad. Pero como hemos ido señalando, aún subsisten numerosos aspectos, que sólo será posible solucionar a través de la investigación arqueológica. En otro plano está el problema de si esta presa puede considerarse un indicio de la implicación de los gobernantes andalusíes en la creación de circuitos de regadío.

En Yemen, el funcionamiento de la presa de Mārib fue posible por la solidez del poder político, y fue la debilidad de este, la que impidió repararla después de su última destrucción. Lo mismo sucedía en el resto de oriente, donde la intervención del príncipe reparando las presas de regadío, es una constante en las fuentes escritas.

¿Y en al-Andalus? Se admite generalmente que, probablemente, los circuitos de regadío andalusíes fueron construidos por los sectores agrarios y campesinos. ¿Pero quienes eran estos? M. Barceló insistió en atribuir la introducción del regadío a comunidades campesinas tribales bereberes (Barceló et alii, 1996). Pero siguen sin aparecer elementos que demuestren ese componente étnico y tribal, y tampoco resulta 
necesario, dada la multiplicidad de influencias que parecen confluir en la formación del regadío. No hay duda de que los «sectores agrarios» estaban integrados por muchos grupos, probablemente con intereses no siempre coincidentes. Desde luego por los propios campesinos que trabajaban sus tierras, independientemente de que su organización se basase en estructuras comunitarias o de otro tipo, pero también por todos los poseedores de tierras, entre los que sin duda había grandes propietarios, como demuestran las excavaciones de Marroquíes Bajos (Jaén) (Salvatierra, 2009), o las grandes almunias de los sectores ligados al poder, a lo largo del tiempo.

La manifestación del poder político del estado es la creación de ciudades (Acién, 1987), que es también conquista de la naturaleza. Como parte de esta última hay que considerar la construcción de jardines y huertas, y en ellas la organización de los cultivos. Estas alcanzan su mayor expansión en los grandes jardines relacionados con los conjuntos palatinos desde los omeyas, a los nazaríes. Pero los mismos no parecen haber sido empleados en sí mismos como expresión del poder de los estados, y menos aún con una intención propagandística. La visión y disfrute de los de Madīnat al-Zahrā' sólo estaba reservada a una elite. En Córdoba está atestiguada la actuación de miembros de la elite en relación a la creación de huertas y jardines, como por ejemplo, en la construcción de la almunia Al-Rummānīya en Córdoba (Arnold et alii, 2008), donde probablemente el placer tenía tanta importancia como la producción. Casos similares parecen ser las que se han atribuido a Ibn Mardanīš en la zona de la pedanía de Monteagudo, en Murcia (Navarro y Jiménez, 1995), o el de la Buhayra de Sevilla (Valor, 2008), aunque en el primer caso se ha defendido la existencia de un programa edilicio con rasgos muy específicos, quizá con matices propagandísticos. Mientras que en el segundo, el reaprovechamiento y reconstrucción del antiguo (probablemente romano) acueducto de los Caños de Carmona que la abastecía de agua, sobre todo en el tramo que va elevado, pudiera tener igualmente una intención propagandista más amplia (Valor, 2008, 195-198). En el caso de Granada, tampoco las complejas estructuras que distribuían el agua dentro de la Alhambra estaban destinadas a ser vistas (Malpica, 1995b). Por tanto, las intervenciones de los gobernantes en la creación de huertas y jardines parece tener más que ver con el placer o la producción agrícola que obtuvieran directamente, que con el uso propagandístico que esa actividad pudiera tener al favorecer a un amplio grupo de individuos, o al mostrar su poder.

Esto hace muy especial la presa sobre el Trujala, construida por el yerno de Ibn Mardanīš y durante mucho tiempo su lugarteniente y compañero en la lucha contra los almohades. Por sus características y finalidad, hay que pensar que más allá del regadío, la presa tenía una función de propaganda, y de enaltecimiento de su constructor, en esos años enfrentado al avance almohade. No hay duda de que esa lámina de agua debía producir una gran impresión vista desde Segura de la Sierra, desde donde hoy se aprecia con claridad el espacio que debía cubrir. La presa del Trujala es una obra impulsada por el poder del Estado, que probablemente tuvo pocos paralelos en la época, ya que la organización de la producción parece haber sido claramente un tema «privado» en la sociedad andalusí. A esa «intromisión» se agregó sin duda la falta de pericia desde el punto de vista de la ingeniería, factores que explican su fracaso.

Es muy posible que, como señala A. Malpica para la del río Darro en Granada-La Alhambra, las presas de derivación fueran de materiales poco sólidos, madera y tierra, teniendo previsto los regantes repararlas cada año, asumiendo la dificultad -y quizá inutilidadde tratar de controlar los cambiantes aportes de agua. La presa de la Garganta del Ciervo era sobre todo un objeto propagandístico, que no tuvo en cuenta la realidad de que el Trujala es un río de caudal muy cambiante, y fue rápidamente destruida. Subsisten importantes restos de la misma y es paradójicamente una muestra del fracaso del estado, al intentar sustituir las prácticas tradicionales en su provecho, sin disponer de los conocimientos ni la tecnología suficientes para ello.

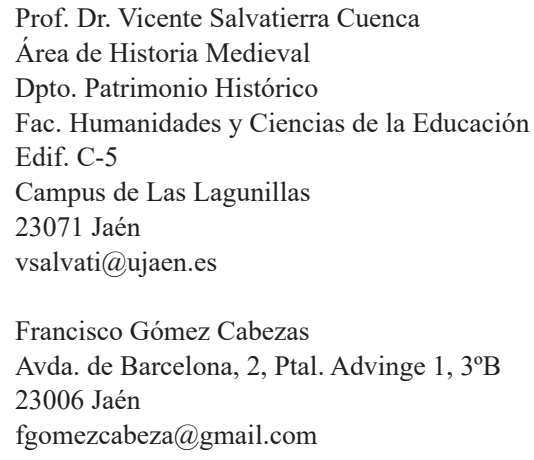

\section{FUENTES ÁRABES}

AL MARRĀKUŠĪ, 1955: Kịtāb al-mu'ŷib fì taljīs ajbār alMugrib. (Lo admirable en el resumen de los noticias del Magrib), trad. Huici Miranda, A., Colección de Crónicas Árabes de la Reconquista, Vol. 4, Tetuán.

IBN AL-ATITR, 1898: Annales du Maghreb et de l'Espagne, trad. Fagnan, Edmond, Argel.

IBN ȘĀHIB AL-ȘĀLAT, 1969: Al-Mann Bi-l-imāma, trad. Huici Miranda, A., Valencia.

AL-IDRĪSİ, 1989: Los caminos de al-Andalus en el siglo XII, Estudio, edición y trad. Jassim Abid Mizal, Madrid.

DIEGO DE GUADIX, 2007: Diccionario de arabismos. Recopilación de algunos nombres arábigos, Estudio preliminar y edición de Ma Águeda Moreno Moreno, Jaén.

\section{BIBLIOGRAFÍA}

ACIÉN, M., 1987: «Madinat al-Zahra en el urbanismo musulmán», Cuadernos de Madīnat al-Zahrā', 1, 11-26. 
AGUIRRE, Fº J. y JIMÉNEZ, M ${ }^{\mathrm{a}}$ C., 1979: Introducción al Jaén islámico, Jaén.

ALMENDRAL, J. Ma , 1986: Jaén desde sus obras públicas, Madrid.

ARNOLD, F., CANTO, A. y VALLEJO, A., 2008: «La almunia de Ar-Rummānīya. Resultados de una documentación arquitectónica», Cuadernos de Madīnat alZahrā', 6, 181-204.

BARCELÓ, C., 2010: Noms aràbics de lloc, 16, 50, 51, Valencia.

BARCELÓ, M., KIRCHNER, H. y NAVARRO, C., 1996: El agua que no duerme, Granada.

BAZZANA, A., CRESSIER, P. y GUICHARD, P., 1988: Les chateaux ruraux d'Al-Andalus. Histoire et archéologie des huşūn du sud-est de l'Espagne, Madrid.

CEBRIÁN, A. y CANO, J., 1992: Relaciones topográficas de los pueblos del reino de Murcia, 1575-1579, Murcia.

CHAVES, B. de, 1975: Apuntamiento legal del dominio solar que por expresas órdenes y reales donaciones pertenece a la Orden de Santiago en todos sus pueblos, Barcelona, Ed. facsimile de la de 1740.

CRESSIER, P., 1986: «Dalias et son territoire: un groupe d'alquerias musulmanes de la Basse Alpujarra (Province d'Almeria)», Actas del XII Congreso de la U.E.A.I. (Málaga 1984), 205-228, Madrid.

CRESSIER, P., 1995: «Hidraúlica rural tradicional de origen medieval en Andalucía y Marruecos. Elementos de análisis práctico», en J. A. González Alcantud y A. Malpica Cuello (eds.), El agua. Mitos, ritos y realidades, 255-286, Barcelona-Granada

CRESSIER, P., 1996: «À propos des apports orientaux dans l'hydraulique agraire d'al-Andalus: observations sur le barrage», en S. Noack (ed.), Spanien und der Orient im Frühen und Hohen Mittelalter, Madrider Beiträge 24, 142-156 y láms. 30-32.

CRESSIER, P. y OSUNA, M M M., 2005: «Loin des lieux communs: la construction des espaces irrigués de la vega de Grenade», en A. Bazzana y J.M. Poisson (eds.), Ruralia $V$. Watermanagement in medieval rural economy/Les usages de l'eau au Moyen Âge, Památky Archeologické, Supplementum 17, 49-54, Praga,

CRUZ AGUILAR, E. de la, 1994: «El reino taifa de Segura», Boletín del Instituto de Estudios Giennenses, 153, 2, 883-914.

DARLES, Ch., JULIEN, Ch. y SCHIETTECATTE, J., 2013: «Contribution à une meilleure compréhension de l'histoire de la digue de Ma'rib au Yémen», en F. Baratte; Ch.J. Robin y E. Rocca (eds.), Regards croisés d'Orient et d'Occident. Les barrages dans l'Antiquité Tardive, 9-70, París.

FERNANDEZ ORDOÑEZ, J.A. ET ALII, 1984: Catálogo de noventa y tres presas y azudes españoles anteriores a 1900, Madrid.

GASPAR Y REMIRO, M., 1980: Historia de Murcia musulmana, Murcia, Reimpresión, de la ed. de Zaragoza 1905.

GENÉQUAND, D., 2013: «Barrages d'époque omeyyade au proche-orient» en F. Baratte; Ch.J. Robin y E. Rocca (eds.), Regards croisés d'Orient et d'Occident, Les barrages dans l'Antiquité Tardive, 103-124, París.
GUICHARD, P., 1990: L'Espagne et la Sicile musulmanes aux $X I^{e}$ et $X I I^{e}$ siècles, Lyon.

HEHMEYER, I. y SCHMIDT, J., 1991: Antike Technologie - Die sabäische Wasserwirtschaft von Mārib, Archäologische Berichte aus dem Yemen V, Maguncia.

HUICI MIRANDA, A., 2000: Historia política del Imperio almohade, Granada, Ed. facsimil, 1956.

LALIENA, C., SESMA, J.A. y UTRILLA, J.F., 1996: «Regadíos andalusíes en el valle medio del Ebro» en Agricultura y regadio en al-Andalus. Síntesis y problemas, 67-84, Almería.

MALPICA, A., 1995a: «De la congruencia y la homogeneidad de los espacios hidráulicos en Al-Andalus», en T. Quesada y A. Malpica (eds.), El agua en la agricultura de Al-Andalus, 25-40, Barcelona.

MALPICA, A., 1995b: «El agua y el poblamiento de La Alhambra de Granada», en T. Quesada y A. Malpica (eds.), El agua en la agricultura de al-Andalus, 119130, Barcelona.

MANZANO, E., 1992: Historia de las sociedades musulmanas en la Edad Media, Madrid.

MARTÍNEZ NUÑEZ, Ma A., 2002: "Yeserías epigrafiadas del Castillo de Santa Catalina (Jaén)», Arqueología y Territorio Medieval, 9, 165-179.

NAVARRO, J. y JIMÉNEZ, P., 1995: «El castillejo de Monteagudo: Qașr ibn Sa'd», en J. Navarro (ed.), Casas y palacios de al-Andalus, 63-103, Madrid.

PORRAS ARBOLEDAS, P., 1997: La orden de santiago en el siglo $X V$, Jaén.

RAE, 1984: Diccionario de la Lengua Española, Real Academia Española, Madrid, $20^{a}$ ed.

SALVATIERRA, V., 1998: «Formación y desarrollo de un territorio andalusí: Las sierras de Cazorla y Quesada (Jaén)», en V. Salvatierra (ed.), Hispania, Al-Andalus, Castilla, 183-219, Jaén.

SALVATIERRA, V., 2001: La crisis del emirato omeya en el Alto Guadalquivir. Introducción a la geografía de la rebelión muladí ( $S$. $I X-X)$, Jaén.

SALVATIERRA, V., 2009: «El agua en la ciudad de Jaén en época andalusí. Una historia entrelazada», Xelb, 9, 259-280.

SALVATIERRA V., CASTILLO, J.C., GÓMEZ, F. y VISEDO, A., 2006: «Evolución de un territorio en época medieval. El valle del Hornos-Trujala (Segura de la Sierra)», en A. Gálvez (ed.), Proyectos de Investigación 2004-2005, 11-82, Jaén.

SALVATIERRA, V. y VISEDO, A., 2008: «Segura de la Sierra y el origen de la articulación de un territorio medieval», en P. Cressier (ed.), Castrum 8. Le château et la ville. Espaces et réseaux (VIe-XIIIe siècle), 135-150, Madrid.

SALVATIERRA, V., VISEDO, A., MONTILLA, I., PÉREZ, S., BEDMAR, C. y CAMPOS, T., 2001: «Las fases islámicas del castillo de Segura de la Sierra (Jaén)», Arqueología y Territorio Medieval, 8, 289-304.

VALLEJO, A., 2010: La ciudad califal de Madinat al-Zahra. Arqueología de su excavación, Córdoba.

VALLVÉ, J., 1986: La división territorial de la España musulamana, Madrid. 
VALOR, M., 2008: Sevilla Almohade, Málaga.

VIGUERAS GONZÁLEZ, M., 2001: Introducción a la historia de los musulmanes en Sierra Segura. 713-1214, Madrid-Siles.
VILLEGAS, L. y GARCÍA, R., 1976: «Relación de los pueblos de Jaén, ordenadas por Felipe II», Boletín del Instituto de Estudios Gienneses, 88-89, 9-304.

Recepción: 04-02-2016

Aceptación: 18-07-2016 